\title{
ENTRE LINHAS, TESOURAS E MÁSCARAS, COSTURANDO SOLIDARIEDADE
}

\author{
Entre hilos, tijeras y barbijos, cosiendo solidario
}

Among threads, scissors and masks, sewing solidarity

\section{Alice Cristina Souza Lacerda Melo de Souza ${ }^{1}$, Cleuza Diogo An- tunes $^{2}$, Andréia Mendonça dos Santos Lima ${ }^{3}$, Luciana Cristina \\ Pereira $^{4}$}

\section{RESUMO}

Este relato descreve as ações desenvolvidas no projeto Entre linhas, tesouras e máscaras, costurando solidariedade, que teve por objetivo fortalecer a extensão no IFRO, Instituto Federal de Rondônia, Campus Ji-Paraná, por meio de parcerias para minimizar os efeitos da pandemia no município, com a confecção e distribuição de máscaras caseiras de tecido a grupos socialmente vulneráveis. Realizado em duas etapas o projeto foi desenvolvido entre os meses de Maio de 2020 a Janeiro de 2021. Conclui-se que o projeto alcançou os objetivos propostos uma vez que as máscaras distribuídas alcançaram grupos vulneráveis colaborando para a proteção dos indivíduos que precisaram circular pela sociedade, além dos grupos que ficaram isolados, como é o caso dos indígenas aldeados.

Palavras-chave: Ações de extensão; Prevenção; Corona Vírus; Máscaras de tecido.

Mestre em Educação; Professora do Instituto Federal de Educação-IFRO.

2 Mestra em Educação Escolar; Bibliotecária do Instituto Federal de Educação-IFRO

3 Mestre, Professora de Língua Inglesa, do Instituto Federal de Educação, Ciência e Tecnologia de Rondônia

4 Especialista; Professora de Língua espanhola do Instituto Federal de Educação, Ciência e Tecnologia de Rondônia) 


\section{ABSTRACT}

The report describes actions developed in the project Among threads, scissors and masks, sewing solidarity, which aimed to strengthen the extension in IFRO, Federal Institute of Rondônia, Campus Ji-Paraná, through partnerships to minimize the effects of the pandemic in the city, with confection and distribution of homemade face masks to socially vulnerable groups. Carried out in two stages, the project was developed from May 2020 to January 2021. It was concluded that the project achieved the proposed objectives since the distributed face masks reached vulnerable groups collaborating to the protection of individuals who needed to circulate in society as well as those who were isolated but in groups, as is the case of the indigenous villagers.

Keywords: Extension actions; Prevention; Coronavirus; Cloth masks.

\section{RESUMEN}

El relato describe las acciones desarrolladas en el proyecto Entre hilos, tijeras y barbijos, cosiendo solidario, que tuvo como objetivo fortalecer la extensión en IFRO, Instituto Federal de Rondônia, Campus Ji-Paraná, a través de alianzas para minimizar los efectos de la pandemia en el municipio, con la producción y distribución de barbijos caseros de tejido para los grupos socialmente vulnerables. Realizado en dos etapas, el proyecto se desarrolló entre los meses de mayo de 2020 a enero de 2021. Se concluye que el proyecto logró los objetivos propuestos ya que los barbijos distribuidos llegaron a grupos vulnerables colaborando para proteger a las personas que necesitaban circular en la sociedad así como los que estaban aislados, aunque en grupos, como es el caso de los indios en las aldeas.

Palabras clave: Acciones de extensión; Prevención; Coronavirus; Barbijos de tejido. 


\section{INTRODUÇÃO}

Desde que os primeiros casos de transmissão do coronavírus foram divulgados pela imprensa internacional e nacional, observou-se uma corrida pelos equipamentos de proteção individual a fim de que estes pudessem ser utilizados no combate e prevenção da doença. Por essa razão, verificamos a escassez desses materiais no mercado mundial.

Ademais, as autoridades competentes solicitaram que esses equipamentos de proteção individual fossem destinados e reservados aos profissionais de saúde que estavam atuando diretamente na pandemia da COVID-19. Dentre esses materiais auxiliadores na não propagação do vírus, estão as máscaras cirúrgicas.

O uso das máscaras foi indicado a princípio somente aos profissionais da saúde, e essa orientação permaneceu controversa até a declaração dada por George Gao, diretor-geral do Centro de Controle e Prevenção de Doenças da China que afirmou "que o maior erro do Ocidente na batalha contra a Covid-19 é não incentivar o uso de máscaras de proteção em massa" (CARBINATO, 2020).

Tal declaração fomentou ainda mais a procura por máscaras diante do mercado já escasso. Essa falta pode ter sido ocasionada por boicote de alguns países, a exemplo da notícia vinculada pelo G1 que os EUA teriam impedido que máscaras fossem enviadas a outros países proibindo a exportação do produto a outras nações (CORONAVÍRUS, 2020).

Entretanto, em meio ao caos provocado pela pandemia, a notícia de que uso das máscaras de tecido, poderiam atuar como barreira ao contágio principalmente entre os assintomáticos trouxe esperança aos demais cidadãos, uma vez que as elas poderiam ser facilmente confeccionadas.

No Brasil, o uso e confecção das máscaras ganhou força após a recomendação do então ministro da Saúde, Luiz Henrique Mandetta (2020) que afirmou: "Máscaras de pano para uso comunitário funcionam muito bem e não são caras de fazer. Porque, agora, é lutar com as armas que a gente tem [...]" (ALARCON, 2020).

Junto com as orientações quanto ao uso das máscaras vieram os questionamentos quanto a sua eficácia, todavia em recente estudo (CAMARGO, et al. 2020, p.12) sugerem seus benefícios: quando demonstram que "[...] a utilização de máscaras faciais padrão TNT e ou outros tipos de máscaras como método adjuvante, associado a ações como a higiene das mãos e outras medidas individuais de proteção podem atuar de forma preventiva."

O mesmo é reforçado no estudos de (TAMINATO, et al. 2020) que afirmam “[...] que a máscara é um recurso a mais na prevenção, que deve sempre vir acompanhada do distanciamento social, medidas de higienização das mãos e etiqueta respiratória." 
Considerando a necessidade de uso das máscaras de proteção no enfrentamento à disseminação da COVID-19 e com o intuito de colaborar com uma rede de solidariedade formada por indígenas, o projeto foi estendido também aos povos indígenas que segundo (MONDARDO, 2020) vêm lutando contra a negligência do Estado brasileiro para a situação de vulnerabilidade em que se encontram esses povos em meio à pandemia do Coronavírus.

Diante dos fatos acima mencionados e visando fomentar práticas efetivas de prevenção, o projeto Entre linhas, tesouras e máscaras, costurando solidariedade, foi idealizado a partir da premissa de que as máscaras caseiras de tecido poderiam colaborar para a não transmissão do vírus, principalmente entre pacientes assintomáticos funcionando como uma proteção para os indivíduos que precisariam circular pela sociedade dado o fato de prestarem serviços essenciais, ou que de modo geral precisaram em determinado momento deixar suas casas e frequentarem espaços públi$\cos$.

\section{PERCURSO METODOLÓGICO}

Este trabalho, do tipo relato de experiência, descreve as ações executadas durante o desenvolvimento do projeto extensionista "Entre linhas, tesouras e máscaras: costurando solidariedade". O mesmo foi desenvolvido em parceria com as costureiras da SAF (Sociedade Auxiliadora Feminina) da $4^{\text {a }}$ igreja Presbiteriana do Brasil, quatro bolsistas do projeto, sendo respectivamente uma estudante do $1^{\mathrm{a}}$ ano do Curso Técnico em Química, duas do curso Licenciatura em Química, uma do curso Análise e Desenvolvimento de Sistemas e por servidores do IFRO Campus Ji-Paraná.

Financiado, inicialmente, pelo Edital No 7/2020/REIT - PROEX/IFRO, de 01 de abril de $2020 \mathrm{~N}^{\mathrm{o}}$ 7/2020, o projeto visou a produção de equipamentos/materiais de proteção e prevenção, objetivando atender principalmente a comunidade não representada pelos profissionais de saúde, e a primeira etapa foi desenvolvida entre os meses de Maio a Outubro de 2020. Posteriormente, com a crescente demanda representada pelo aumento de números de pessoas infectadas no Estado de Rondônia, o projeto recebeu um aporte financeiro do Campus Ji-Paraná, sendo desenvolvido entre os meses de Outubro de 2020 a Janeiro de 2021.

Os itens necessários foram adquiridos pela coordenadora do projeto e disponibilizados às costureiras voluntárias e bolsistas em seus lares. Estas confeccionaram, higienizaram, passaram e embalaram as máscaras. Houve a identificação dos kits (etiqueta contendo o nome do projeto, colaboradores e instruções de higienização e uso das máscaras) e distribuição aos demandantes.

Durante a entrega, depoimentos foram solicitados e publicados nas matérias vinculadas no 
site do IFRO para publicização do projeto tal como era solicitado pelo Edital financiador.

\section{RESULTADOS}

A primeira etapa atendeu ao objetivo previsto inicialmente no projeto que consistia no fortalecimento da rede de costureiras voluntárias para auxiliarem as bolsistas na confecção das máscaras. Para o sucesso dessa ação, a presidente de um grupo de mulheres (SAF) foi contatada e a proposta levada as 07 (sete) participantes que aceitaram a parceria. Em depoimento, uma das parceiras afirmou que ela se sentiu extremamente gratificada em poder contribuir com essa iniciativa "[...] senti a necessidade de ajudar, doando mão de obra, pois essa é a forma que eu pude colaborar. Para mim é muito gratificante ajudar o próximo". (IFRO, 17 jun. 2020).

Para que as costuras fossem efetivadas, os materiais foram entregues e recolhidos nas casas das voluntárias e bolsistas pela coordenadora, essa precaução foi tomada a fim de se atender às medidas de combate ao coronavírus durante a pandemia.

Assim que as primeiras máscaras ficaram prontas, a entrega foi realizada no Campus e contou com a presença da secretária municipal do Meio Ambiente que efetuou o repasse à Cooperativa de Catadores de Materiais Recicláveis de Ji-Paraná (COOCAMARJI) e aos funcionários dos Viveiro Municipal, ao representante da Colônia dos Pescadores Z-9, de uma professora do IFRO que intermediou a doação ao Coletivo Campanha: Articulação de Suporte ao Enfrentamento a Covid-19 pelos povos indígenas de Rondônia, Sul do Amazonas e Noroeste do Mato Grosso e da representante da SAF.

Imagem 1: Entrega simbólica das máscaras.

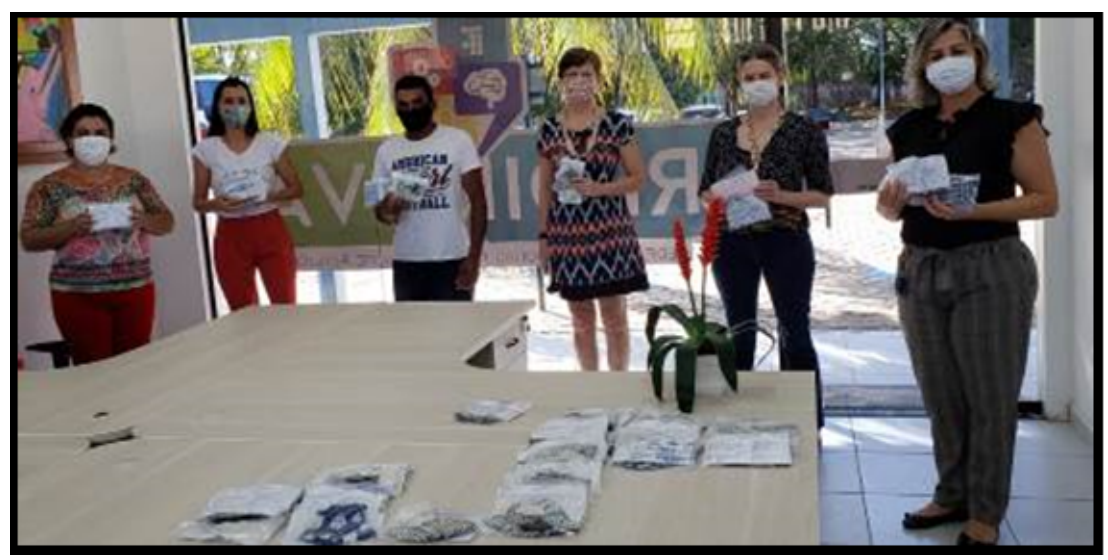

Fonte: Alice Cristina ( 2020). 
Outro grupo contemplado foram os moradores do bairro Bosque dos Ipês, localizado numa área periférica do município de Ji-Paraná, que receberam 294 máscaras em seus lares durante uma campanha de limpeza promovida pelas Secretarias Municipais do Meio Ambiente (SEMEIA) e de Obras e Serviço Público (SEMOSP).

Aos moradores de rua do município, a distribuição foi realizada tanto na primeira como na segunda etapa, foram repassadas 166 máscaras por meio da representante do projeto "Entrega e Banho Solidário". Esse projeto atua, realizando entregas de alimentos (marmitas, sucos, doces), bem como são oferecidos banhos com distribuição de itens de higiene pessoal, roupas e cortes de cabelo e barba.

Imagem 2: Entrega das máscaras.

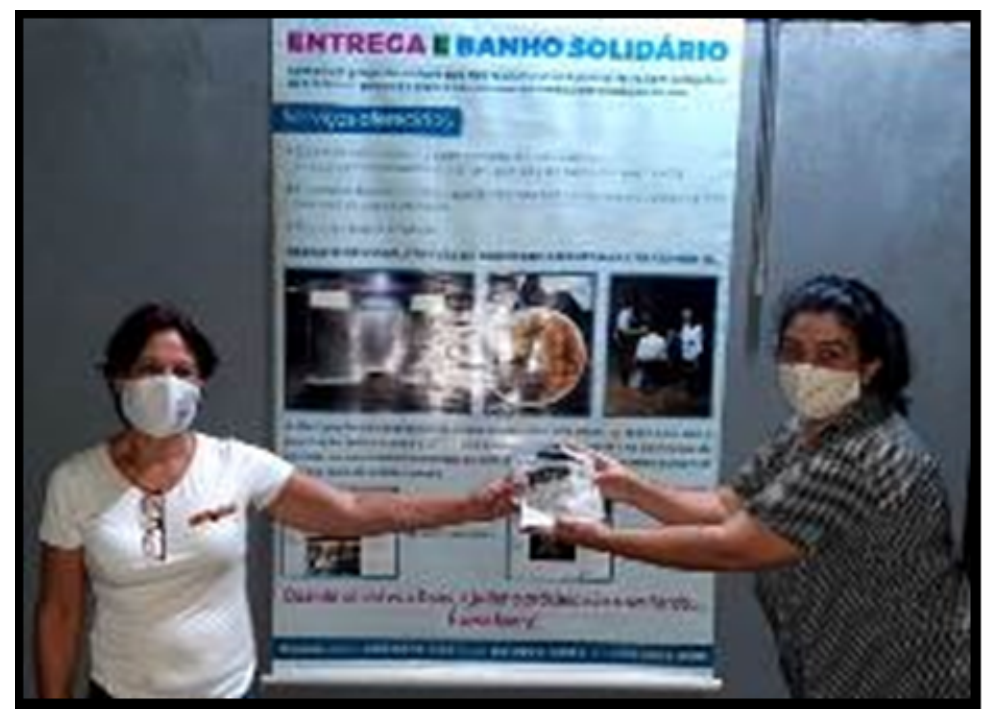

Fonte: Alice Cristina (2020).

Durante o desenvolvimento do projeto, surgiu uma forte demanda para a entrega de máscaras entre os povos indígenas (aldeados e não-aldeados) distribuídos em diferentes municípios do Estado de Rondônia e estados vizinhos como Mato Grosso e Amazonas, dentre os povos atendidos estão o povo Zoró, Palmari, Mura.

Os povos indígenas durante o avanço da pandemia acabaram por se tornar um grupo extremamente vulnerável e por este motivo 1.681máscaras foram remanejadas para atendê-los, inicialmente este grupo não estava previsto para ser atendido pelo projeto. Ao falar sobre importância dessas máscaras, o colaborador do projeto Adilton Furtado Campos, que intermediou a entrega das más- 
caras entre a comunidade Oro Mon, no município de Guajará-Mirim, destacou que devido a uma maior integração dos indígenas à sociedade, a máscara era extremamente importante

[...] porque hoje eles estão bem integrados na nossa sociedade. Ou seja, eles se deslocam das suas aldeias para a cidade com frequência para receber benefícios sociais do Governo e fazer suas compras. Eles também acabam tendo contato com não indígenas que vão até as aldeias, como é o caso dos profissionais de saúde. Então a máscara é um item indispensável para a proteção deles durante a pandemia. (IFRO, 10 jul. 2020)

Para que as máscaras alcançassem os indígenas, foram firmadas ao longo do projeto, parcerias com a Campanha: Articulação de Suporte ao Enfrentamento a Covid-19 pelos povos indígenas de Rondônia, Sul do Amazonas e Noroeste do Mato Grosso e a Casa de Apoio a Saúde Indígena de Ji-Paraná (CASAI) e com o projeto Costuras do Amor que vinha realizando uma forte ação junto aos indígenas.

Imagem 3: Membros da CASAI realizando as doações entre os indígenas.

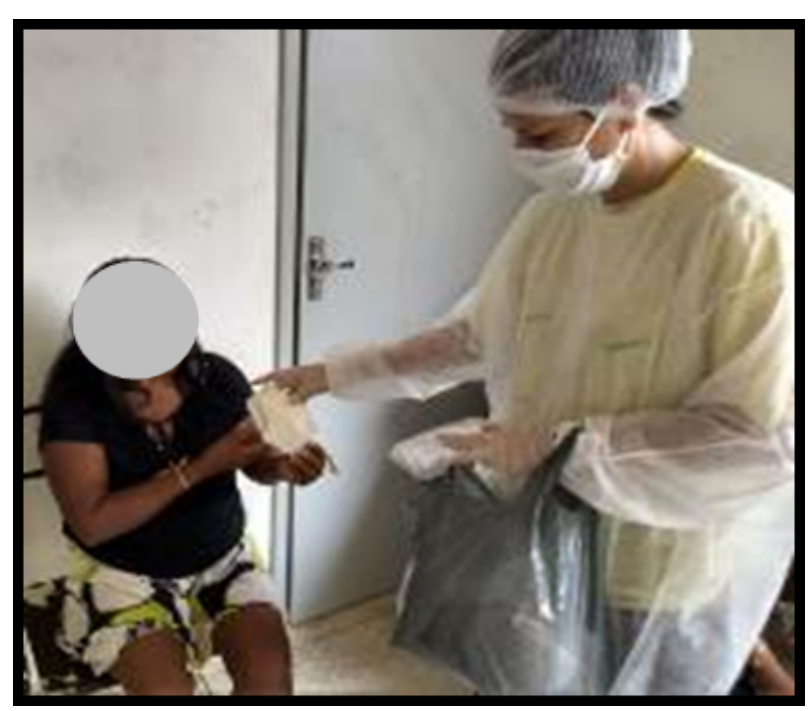

Fonte: Foto cedida por Luciane (2020).

Outras duas instituições assistidas foram uma Escola de Ensino Estadual localizada no município de Ji-Paraná (45 máscaras) e o próprio IFRO, que designou 85 máscaras aos servidores e a Coordenação de Serviços Gerais do Campus Ji-Paraná a fim de atender a demandas de entrada de terceiros e servidores que durante a pandemia precisaram acessar o Campus. 
Aos alunos atendidos pelo Programa Nacional de Alimentação Escolar (PNAE), 200 máscaras foram doadas, estes as receberam junto com os kits de alimentos entregues pelos servidores em seus lares.

Ao $2^{\circ}$ Grupamento do Corpo de Bombeiros Militar, foram doadas 185 máscaras (adultas e infantis) para serem distribuídas às famílias das crianças atendidas pela Campanha Criança Feliz 2020, idealizada pelos bombeiros do município de Ji-Paraná. Alguns servidores do Campus aderiram a Campanha doando brinquedos.

Imagem 4: Entrega de máscaras ao Corpo de Bombeiros.

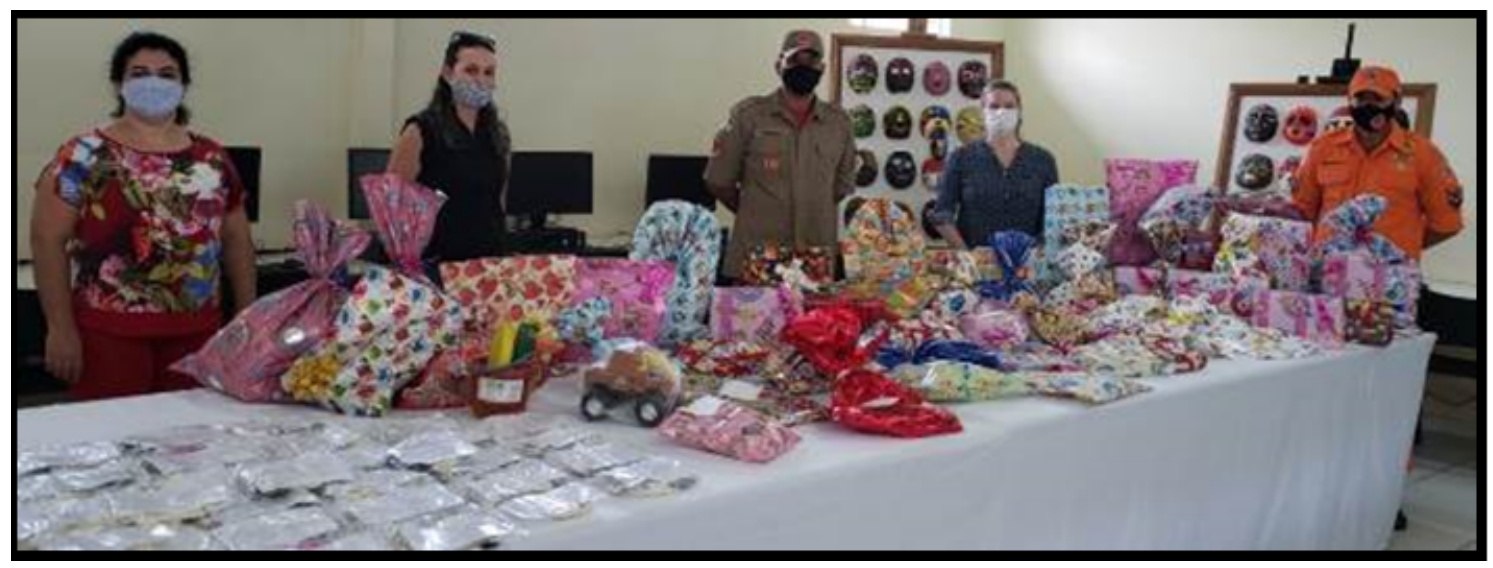

Fonte: Alice Cristina (2020).

O Programa Mesa Brasil, coordenado pelo SESC, foi assistido com 469 máscaras durante as duas etapas. A ação realizada pelo Instituto foi divulgada, durante uma live solidária no dia 1112-2020, organizada pelo SESC para arrecadação de alimentos para composição de cestas básicas. Houve parceria com outro projeto que estava sendo desenvolvido no Campus, intitulado "Produção e distribuição de sabão caseiro em comunidades carentes - ação de enfrentamento à Covid-19”, que destinou 270 barras de sabão ao Programa Mesa Brasil. Junto a doação de máscaras e sabão, foram incorporadas doações de alimentos, de servidores do Campus para serem incorporadas as cestas básicas organizadas pelo SESC.

Outra ação contemplada foi realizada pelo Posto da Polícia Rodoviária Federal, localizado no município de Ji-Paraná (RO) que distribuiu cestas básicas para as famílias das crianças em tratamento de câncer no Estado. A campanha foi idealizada em alusão a dia 23 de Novembro, considerado Dia Nacional de Combate ao Câncer Infantil. 
Foram doados à Campanha 180 máscaras em tecido e 120 barras de sabão resultado da parceria com o Produção e distribuição de sabão caseiro em comunidades carentes -ação de enfrentamento à Covid-19.

Por fim, foram repassadas 20 máscaras a uma bolsista do projeto que as distribuíram entre duas famílias no município de Nova União-RO, 50 máscaras a um grupo de voluntários que realiza distribuição de alimentos junto a moradores de rua em Curitiba-PR e 50 máscaras a 10 famílias assistidas com cestas básicas organizadas por servidores do Campus .

No decorrer do projeto houve a necessidade se destinar mais 255 máscaras à Cooperativa de Catadores de Materiais Recicláveis de Ji-Paraná (COOCAMARJI), visto que esse grupo realiza um trabalho essencial no município e precisavam renovar e trocar suas máscaras com maior frequência. Junto a esse grupo também foram entregues 180 barras de sabão, resultantes da parceria com o projeto Produção e distribuição de sabão caseiro em comunidades carentes - ação de enfrentamento à Covid-19.

Por fim, ocorreu a doação de 300 (máscaras) ao $2^{\circ}$ Batalhão de Polícia Militar - Batalhão Tiradentes, a entrega foi efetuada no Campus Ji-Paraná.

Imagem 5 - Entrega de máscaras ao representantes do $2^{\text {a }}$ batalhão de Polícia Militar.

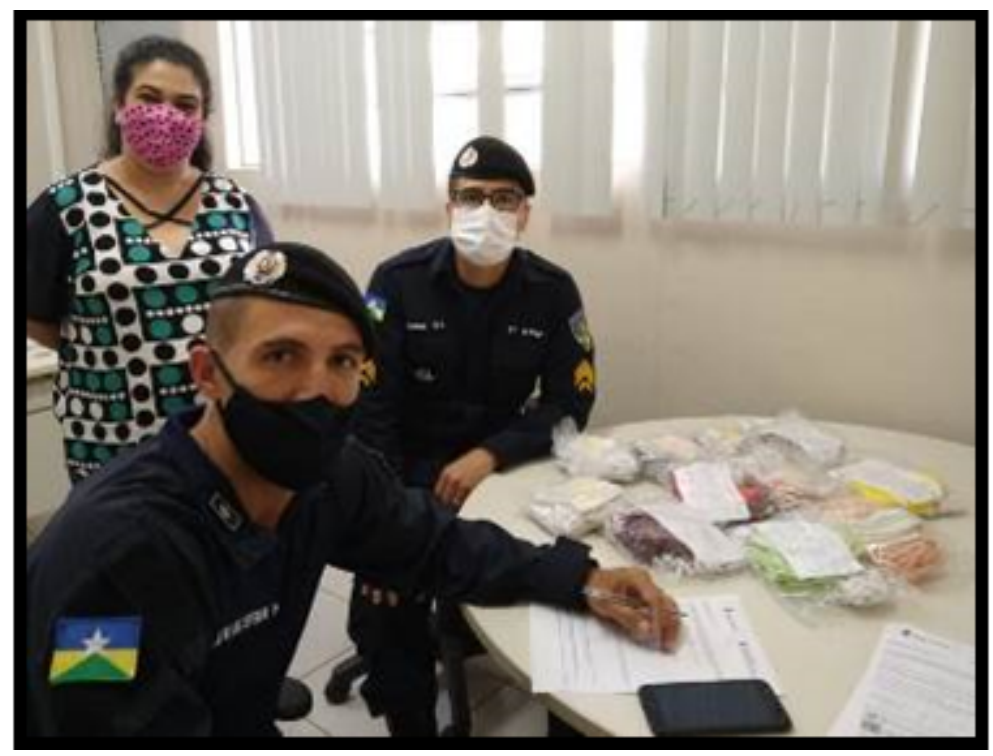

Fonte: Alice Cristina (2020).

Diferentemente da $1^{\mathrm{a}}$ etapa que o edital previa tão somente a aquisição de material para o 
custeio, a contrapartida do Campus possibilitou a aquisição de 07 máquinas de costura que foram adquiridas e doadas sendo incorporadas ao patrimônio do IFRO.

Imagem 6: Máquinas de costuras adquiridas na $2^{\mathrm{a}}$ etapa do projeto.

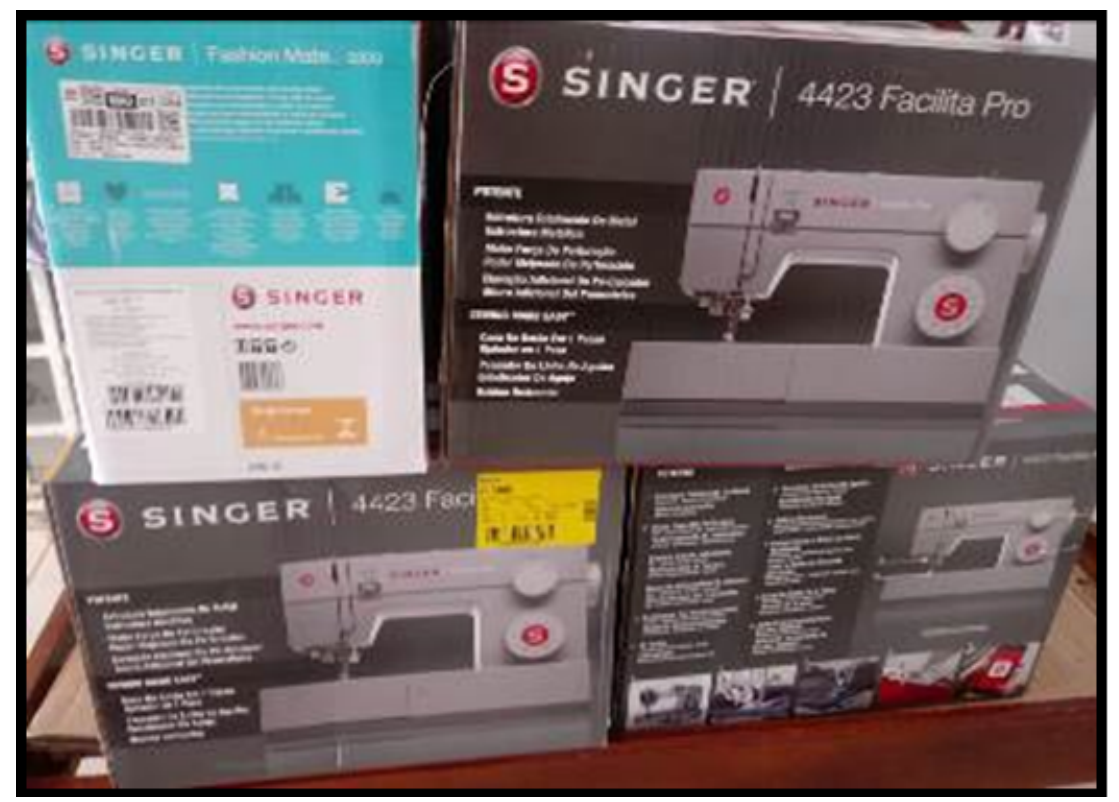

Fonte: Alice Cristina (2020).

\section{CONSIDERAÇÕES FINAIS}

Acreditamos que o projeto alcançou os objetivos propostos uma vez que as máscaras distribuídas alcançaram os grupos vulneráveis inicialmente previstos, bem como extrapolou seu campo de atuação ao atender outras demandas que se apresentaram a exemplo dos povos indígenas que receberam a maior parte das máscaras confeccionadas. Cumpriu o objetivo de fortalecimento da extensão universitária no IFRO, pois os alunos participantes puderam conhecer diferentes realidades comunitárias e contribuir para mudar essas realidades nesse período de pandemia.

Outro ponto positivo, refere-se ao fortalecimento de parcerias, estas foram sendo ampliadas no decorrer do desenvolvimento do projeto, o que nos leva a inferir que o IFRO ao financiar e ampliar ações extensionista se fortalece e se firma perante à sociedade como uma instituição que acolhe as demandas trazidas, oferecendo soluções pautadas no tripé do ensino, pesquisa e extensão.

Por fim, acreditamos que as máscaras distribuídas pelo projeto serviram como uma prevenção para os indivíduos que precisaram circular pela sociedade bem como para os que por questões culturais ficaram isolados, porém em grupos, como é o caso dos indígenas aldeados. 
Por fim, destacamos que ao todo foram distribuídas 4240 máscaras. Devido à relevância e ao alcance do projeto, este recebeu uma contrapartida financeira do Campus, por este motivo foi realizado em duas etapas, inclusive com a ampliação de bolsas para os estudantes, o que é essencial neste momento garantindo que os discentes recebam um aporte financeiro enquanto se dedicam a projetos.

Outro ponto favorável foi o envolvimento dos Campus nas ações que foram sendo incorporadas ao projeto, uma vez que houve doações pessoais de alimentos e brinquedos e também destacamos a parceria entre projetos, neste caso, o de produção de sabão, que acabou culminando em mais uma ação de prevenção à pandemia.

\section{REFERÊNCIAS}

ALARCON, Tatiana. Máscaras caseiras podem ajudar na prevenção contra o Coronavírus. Ministério da Saúde: Últimas notícias, 02 abr. 2020, 19h00. Disponível em: https://www.saude.gov. br/noticias/agencia-saude/46645-mascaras-caseiras-podem-ajudar-na-prevencao-contra-o-coronavirus.sso Acesso em: 06 abr. 2020.

CAMARGO, Maria Cristina de et al. Eficácia da máscara facial (TNT) na população para a prevenção de infecções por coronavírus: revisão sistemática. Ciência e Saúde Coletiva, v. 25, n.9, p. 3365-3375, 2020. Disponível em: https://www.scielo.br/scielo.php?pi$\mathrm{d}=\mathrm{S} 1413-81232020000903365 \&$ script=sci_arttext. Acesso em: 06 abr. 2020.

CARBINATTO, Bruno. Não usar máscara durante a pandemia é um erro, alertam cientistas chineses. Superinteressante, São Paulo, 30 mar. 2020, 20h18. Disponível em: https://super.abril. com.br/saude/nao-usar-mascara-durante-a-pandemia-e-um-erro-alertam-cientistas-chineses/. Acesso em: 06 abr. 2020.

CORONAVÍRUS: EUA são acusados de 'pirataria' e 'desvio' de equipamentos que iriam para Alemanha, França e Brasil. Globo.com: mundo, São Paulo, 04 abr. 2020, 10h54. Disponível em: https://g1.globo.com/mundo/noticia/2020/04/04/coronavirus-eua-sao-acusados-de-pirataria-e-desvio-de-equipamentos-que-iriam-para-alemanha-franca-e-brasil.ghtml. Acesso em: 06 abr. 2020.

IFRO. Instituto Federal de Rondônia. Campus Ji-Paraná entrega 550 máscaras no projeto "Entre linhas , tesouras e máscaras, costurando solidariedade". Portal do IFRO: Notícias, Porto Velho, 17 jun. 2020. Disponível em: https://portal.ifro.edu.br/. Acesso em: 20 jun. 2020.

IFRO. Instituto Federal de Rondônia. Projeto do Campus Ji-Paraná destina doações de máscaras para indígenas de Guajará-Mirim. Portal do IFRO: Notícias, Porto Velho, 10 jul. 2020. Disponível em: https://portal.ifro.edu.br/. Acesso em: 11 jul. 2020.

MONDARDO, M. Povos indígenas e comunidades tradicionais em tempos de pandemia da Co- 
vid 19 no Brasil: estratégias de luta e r-existência. Finisterra, Lisboa, v. 55, n.115 p. 81-88, 2020. Número Especial: Covid 19. Disponível em: https://revistas.rcaap.pt/finisterra/article/view/20364. Acesso em: 18 abr. 2021.

TAMINATO, Monica et al. Máscaras de tecido na contenção de gotículas respiratórias - revisão sistemática. Acta Paul. Enferm., São Paulo, v. 33, p. 1-11, 2020. Disponível em: https://www.scielo. br/scielo.php?script $=$ sci_abstract\&pid $=$ S0103-21002020000100600\&lng $=$ en\&nrm=iso\&tlng $=$ pt. Acesso em: 06 abr. 2020. 